\title{
COMMENTARY
}

\section{The obesity paradox in the ICU: real or not?}

\author{
Roland N Dickerson* \\ See related research by Arabi et al., http://ccforum.com/content/17/2/R72
}

\begin{abstract}
The obesity paradox has been used to describe the observed phenomenon described by several studies that indicated improved survival for critically ill patients with mild to moderate obesity when compared with their lean counterparts. The study by Arabi and coworkers challenges the obesity paradox concept for critically ill obese patients with septic shock. Their data indicate that obesity, per se, does not significantly improve mortality when outcomes are adjusted for differences in baseline characteristics and sepsis interventions. Further studies are needed to assess the influence of body weight, lean weight, and fat mass for optimizing fluid resuscitation, pharmacotherapy, and nutritional therapy for critically ill patients with sepsis.
\end{abstract}

In the previous issue of Critical Care, Arabi and coworkers examined the effect of obesity upon clinical outcomes following septic shock in a large multicenter cohort study [1]. The worldwide obesity epidemic has led to numerous studies that examined the impact of obesity upon clinical outcomes during critical illness over the past decade. Although the data are conflicting, the prevailing theme is that increased morbidity is associated with an increasing body mass index (BMI; weight $(\mathrm{kg}) /$ height ${ }^{2}\left(\mathrm{~m}^{2}\right)$ ) above normal [2] but a U-shaped curve may be present when relating BMI to survival [3]. Malnourished patients with low BMI $\left(<18.5 \mathrm{~kg} / \mathrm{m}^{2}\right)$ and those with severe class III obesity (BMI $\geq 40 \mathrm{~kg} / \mathrm{m}^{2}$ ) would thus be expected to have the worse outcomes. Because obesity has long been established as a causative factor in the development of diabetes, congestive heart failure, and other obesity-related co-morbidities, improved ICU survival for those with class I and class II obesity (BMI = 30 to $39.9 \mathrm{~kg} / \mathrm{m}^{2}$ ) compared with those with a normal BMI (20 to $\left.25 \mathrm{~kg} / \mathrm{m}^{2}\right)$ seems incongruent or opposite of

*Correspondence: rdickerson@uthsc.edu

Department of Clinical Pharmacy, University of Tennessee Health Science Center, 881 Madison Avenue, Suite 345, Memphis, TN 38163, USA what would be expected. The term obesity paradox has therefore been used to describe the observed phenomenon of improved survival for critically ill patients with obesity when compared with their lean counterparts.

Etiologies for this presumed paradox are not clear. Emerging research indicates that adipose cells may mediate a range of short-term beneficial functions in response to sepsis or stress despite the chronic inflammatory and detrimental health effects from obesity. Adipose tissue is a functional organ capable of altering metabolism and secreting immune-modulating chemokines, and not just a depot for excess energy as assumed in the past [4]. Leptin, secreted from adipose tissue, augmented the immune response and improved bacterial clearance in animals [5]. Critically ill septic patients who survived from sepsis had threefold higher plasma concentrations of leptin compared with those who died [6]. Lipoproteins, apoproteins, and eicosanoid-derived resolvins and protectins have been shown to neutralize lipopolysaccharide, to stimulate clearance of inflammatory debris, and to exert direct anti-inflammatory actions $[7,8]$.

It has been argued that the potential beneficial effect of obesity upon survival for the ICU patient is not a real phenomenon, but is probably reflective of selection bias in the study design without adequately adjusting for confounding factors that may have influenced clinical outcomes. A strength of Arabi and colleagues' study was that mortality was evaluated using the raw data as well as adjusting for differences in baseline characteristics with or without differences in sepsis interventions [1]. Their raw unadjusted data reflected the obesity paradox paradigm - that obese patients had a lower odds ratio for mortality than normal-weight subjects. However, after adjusting for confounders, the impact of obesity was reduced to, at best, a statistically insignificant trend. Their data would indicate that obesity, per se, did not significantly improve survival from septic shock [1].

The investigators postulated that how obese and nonobese patients were managed during resuscitation and antibiotic therapy may have influenced their survival. Since therapeutic interventions did not take into consideration the large variations in BMI among patients, the patients with class III obesity received one-half of the amount of fluid that the underweight group received 
when normalized to body weight. The investigators implied that lean patients may have been over-resuscitated, which has been shown to have detrimental effects including prolonged duration of mechanical ventilation [9]. Additionally, there is a paucity of literature regarding how pharmacokinetic properties of many drugs are altered during critical illness for patients with obesity [10]. Finally, most studies examining the obesity paradox, including this one, did not closely evaluate nutrition therapy. Early initiation of nutrition therapy decreases infectious morbidity for critically ill surgical and trauma patients [11]. Provision of higher amounts of protein has been associated with improved survival during critical illness [12,13], whereas preliminary evidence indicates that excessive caloric intake worsens morbidity particularly for obese patients [14].

In summary, the important work of Arabi and coworkers challenges the validity of the obesity paradox concept for critically ill patients with septic shock [1]. Additionally, their data compel clinician scientists to conduct future research towards better defining optimal fluid resuscitation, pharmacotherapy, and nutrition therapy that considers the wide range in BMI, lean weight, and fat mass observed for these complex patients.

\section{Abbreviations}

BMI, body mass index.

\section{Competing interests}

The author declares that he has no competing interests.

Published: 12 June 2013

\section{References}

1. Arabi YM, Dara SI, Tamim HM, Rishu AH, Bouchama A, Khedr MK, Feinstein D, Parrillo JE, Wood KE, Keenan S, Zanotti S, Martinka G, Kumar A, Kumar A: Clinical characteristics, sepsis interventions and outcomes in the obese patients with septic shock: an international multicenter cohort study. Crit Care 2013, 17:R72.

2. Akinnusi ME, Pineda LA, El Solh AA: Effect of obesity on intensive care morbidity and mortality: a meta-analysis. Crit Care Med 2008, 36:151-158.

3. Hutagalung R, Marques J, Kobylka K, Zeidan M, Kabisch B, Brunkhorst F, Reinhart K, Sakr Y: The obesity paradox in surgical intensive care unit patients. Intensive Care Med 2011, 37:1793-1799.

4. Hauner $\mathrm{H}$ : Secretory factors from human adipose tissue and their functional role. Proc Nutr Soc 2005, 64:163-169.

5. Druml W: ICU patients: fatter is better? Intensive Care Med 2008, 34:1961-1963.

6. Bornstein SR, Licinio J, Tauchnitz R, Engelmann L, Negrao AB, Gold P, Chrousos GP: Plasma leptin levels are increased in survivors of acute sepsis: associated loss of diurnal rhythm, in cortisol and leptin secretion. $J$ Clin Endocrinol Metab 1998, 83:280-283.

7. Wendel M, Paul R, Heller AR: Lipoproteins in inflammation and sepsis. II. Clinical aspects. Intensive Care Med 2007, 33:25-35.

8. Serhan CN, Chiang N, Van Dyke TE: Resolving inflammation: dual antiinflammatory and pro-resolution lipid mediators. Nat Rev 2008, 8:349-361.

9. National Heart, Lung, and Blood Institute Acute Respiratory Distress Syndrome Clinical Trials Network; Wiedemann HP, Wheeler AP, Bernard GR, Thompson BT, Hayden D, deBoisblanc B, Connors AF, Jr, Hite RD, Harabin AL: Comparison of two fluid-management strategies in acute lung injury. NEngl J Med 2006, 354:2564-2575.

10. Erstad BL: Dosing of medications in morbidly obese patients in the intensive care unit setting. Intensive Care Med 2004, 30:18-32.

11. Marik PE, Zaloga GP: Early enteral nutrition in acutely ill patients: a systematic review. Crit Care Med 2001, 29:2264-2270.

12. Allingstrup MJ, Esmailzadeh N, Wilkens Knudsen A, Espersen K, Hartvig Jensen T, Wiis J, Perner A, Kondrup J: Provision of protein and energy in relation to measured requirements in intensive care patients. Clin Nutr 2012, 31:462-468.

13. Weijs PJ, Stapel SN, de Groot SD, Driessen RH, de Jong E, Girbes AR, Strack van Schijndel RJ, Beishuizen A: Optimal protein and energy nutrition decreases mortality in mechanically ventilated, critically ill patients: a prospective observational cohort study. JPEN J Parenter Enteral Nutr 2012, 36:60-68.

14. Dickerson RN, Boschert KJ, Kudsk KA, Brown RO: Hypocaloric enteral tube feeding in critically ill obese patients. Nutrition 2002, 18:241-246.

doi:10.1186/cc12715

Cite this article as: Dickerson RN: The obesity paradox in the ICU: real or not? Critical Care 2013, 17:154. 